\title{
Fully Fuzzy Multi-Level Linear Programming Problem
}

\author{
O. E. Emam \\ Department of Information \\ Systems, Faculty of Computer \\ Science and Information, \\ Helwan University, Egypt.
}

\author{
E. Fathy \\ Department of Mathematics, \\ Faculty of Science, Helwan \\ University, \\ Egypt
}

\author{
M. A. Helmy \\ Department of Basic Science, \\ Elgazeera High Institute for \\ Engineering and Technology, \\ Egypt.
}

\begin{abstract}
This paper focuses on the solution of fully fuzzy multi-level linear programming (FFMLLP) Problem, where all of its decision parameters and variables are fuzzy numbers. An algorithm depending on the fuzzy decision approach and bound and decomposition method will be developed to find a fuzzy optimal solution for the problem under consideration. The main results obtained in this paper will be clarified by an illustrative numerical example.
\end{abstract}

\section{Keywords}

Multi-level programming; Fuzzy decision approach; Bound and decomposition method; Fuzzy linear programming.

\section{INTRODUCTION}

The linear programming in which some parameters are fuzzy numbers is called fuzzy linear programming (FLP). The FLP was formulated firstly by Zimmermann ${ }^{[1]}$. Thereafter, many researchers studied several types of the FLP problems and introduced a variety of algorithms for solving these problems ${ }^{[2][3][4]}$. All the previous works based on changing the FLP into the corresponding crisp linear programming and then find its fuzzy optimal solution.

The FLP in which all decision parameters and variables are fuzzy numbers is called fully fuzzy linear programming (FFLP $)^{[5][6][7]}$. P. Pandian ${ }^{[8]}$ introduced the level-sum method to compute an optimal fuzzy solution to FFLP problem which based on the multi-objective linear programming and the simplex method.

M. Jayalakshmi and P. Pandian ${ }^{[9]}$ proposed a bound and decomposition method to find an optimal fuzzy solution for the FFLP problem. The introduced method decomposed the FFLP problem into three crisp linear programming with bounded variables constraints and then found the fuzzy optimal solution by solving these problems independently and by using its optimal solutions.

In the field of mathematical programming, decentralized planning problems with multiple decision makers were solved in multi-level or hierarchical decision making organizations through developing multi-level optimization programming techniques. These techniques became more important for the decentralized organizations, where each unit or department independently seeks its own interest, but is influenced by the actions of other units.

Multi-level programming (MLP) problem is a sequence of multiple optimization problems in which the constraint area of one is decided by the solution of other decision makers. The sequence of the play is very important and the decision of the upper-level limitations affects the decision of the lower-levels [10][11].

Fuzzy programming approach implies that the upper level decision maker defines his/her objective functions and constraints with possible tolerances. This information is delivered to the lower level decision maker who defines his/her objective functions and constraints, taking goals of the upper level decision maker into consideration. In the decision process, the lower level decision maker solves a fuzzy programming problem with the set of constraints on an overall satisfactory degree of the upper level decision maker. If the suggested solution is not satisfactory to the upper level decision maker, the upper level decision maker must update his/her former objective functions and constraints as well as his/her corresponding tolerances, also the lower level decision maker must do the same until a satisfactory solution is reached .

M.S. Osman et al. ${ }^{[12]}$ proposed a three-planner multi-objective decision-making model and solution method for solving the three-level non-linear multi-objective decision-making (TLNLMODM) problem. This method used the concept of tolerance membership function and multi-objective optimization at every level to develop a fuzzy Max-Min decision model for generating satisfactory solution for (TLNLMODM) problem.

O. M. Saad and M. S. Hafez ${ }^{[13]}$ introduced a fuzzy approach for solving the bi-level integer linear fractional programming (BLILFP) problem. At the first phase of the solution algorithm and to avoid the complexity of non-convexity nature of the constraints, the cutting-plane algorithm was used to construct the convex hull equivalent to the original set of constraints, and then the Charnes \& Cooper transformation was used to obtain the integer solution which convert the BLILFP problem to an equivalent bi-level linear programming (BLLP) problem. At the second phase, a membership function was constructed to develop a fuzzy model for generating the optimal integer solution for the bilevel integer linear fractional programming problem.

O. M. Saad and O. E. Emam ${ }^{[14]}$ focused on a solution approach of bi-level integer linear fractional programming problem with individual chance constraints (CHBLILFP). The basic idea of this approach was to convert the probabilistic nature of this problem into a deterministic bi-level integer linear fractional programming BLILFP problem.

E. A. Youness, O. E. Emam and M.S. Hafez ${ }^{[15]}$ presented an algorithm for solving bi-level multi-objective fractional integer programming problem with fuzzy numbers in the constraints (FBLMOFIPP) based on Taylor series and the Kuhn Tucker conditions.

This paper is organized as follows: it begins in Section 2 by formulating the model of a fully fuzzy multi-level linear programming problem. Section 3 involves the concept of bound and decomposition method for solving a FFMLLP problem. Fuzzy decision approach for MLLP problem is introduced in section 4. An algorithm followed by a flowchart to find the fuzzy optimal solution of the proposed problem is introduced in Section 5 and Section 6. In Section 7, it gives an 
illustrative numerical example to clarify the results. Finally, Summary and concluding remarks are reported in Section 8.

\section{FULLY FUZZY MULTI-LEVEL}

\section{LINEAR PROGRAMMING PROBLEM}

Fully fuzzy multi-level linear programming (FFMLLP) problem may be formulated as follows:

$\left[1^{\text {st }}\right.$ level $]$ :

$\max _{\tilde{\mathrm{x}}_{1}} \tilde{\mathrm{F}}_{1}=\sum_{\mathrm{j}=1}^{\mathrm{n}} \tilde{\mathrm{c}}_{\mathrm{ij}} \otimes \tilde{\mathrm{x}}_{\mathrm{j}}$,

where $\tilde{\mathrm{x}}_{2}, \tilde{\mathrm{x}}_{3}, \ldots, \tilde{\mathrm{x}}_{\mathrm{n}}$ solves,

$\left[2^{\text {nd }}\right.$ level $]$ :

$\max _{\tilde{\mathrm{x}}_{2}} \tilde{\mathrm{F}}_{2}=\sum_{\mathrm{j}=1}^{\mathrm{n}} \tilde{\mathrm{g}}_{\mathrm{ij}} \otimes \tilde{\mathrm{x}}_{\mathrm{j}}$

where $\tilde{x}_{3}, \ldots, \tilde{x}_{\mathrm{n}}$ solves,

$\left[\mathrm{m}^{\text {th }}\right.$ level $]$ :

$\max _{\tilde{\mathrm{x}}_{\mathrm{m}}} \tilde{\mathrm{F}}_{\mathrm{m}}=\sum_{\mathrm{j}=1}^{\mathrm{n}} \tilde{\mathrm{d}}_{\mathrm{ij}} \otimes \tilde{\mathrm{x}}_{\mathrm{j}}$,

where $\tilde{\mathrm{x}}_{\mathrm{m}+1}, \ldots, \tilde{\mathrm{x}}_{\mathrm{n}}$ solves,

subject to

$$
\begin{aligned}
\sum_{j=1}^{n} \tilde{a}_{r j} \otimes \tilde{x}_{j} & \leq \tilde{b}_{r}(r=1,2, \ldots, k), \\
\tilde{x}_{j} & \geq \tilde{0}(j=1,2, \ldots, n) .
\end{aligned}
$$

Where $\tilde{x}_{j},(j=1,2, \ldots, n)$ be fuzzy variables indicating the $\mathrm{i}^{\text {th }}$ decision level choice $(\mathrm{i}=1,2, \ldots, \mathrm{m})$. The parameters $\tilde{\mathrm{c}}_{\mathrm{ij}}, \tilde{\mathrm{g}}_{\mathrm{ij}}, \tilde{\mathrm{d}}_{\mathrm{ij}}, \tilde{\mathrm{a}}_{\mathrm{rj}}$ and $\tilde{\mathrm{b}}_{\mathrm{r}},(\mathrm{j}=1,2, \ldots, \mathrm{n}),(\mathrm{i}=1,2, \ldots, \mathrm{m})$, $(\mathrm{r}=1,2, \ldots, \mathrm{k})$ are fuzzy numbers.

\subsection{Definition ${ }^{[9]}$}

A triangular fuzzy number $\tilde{\theta}=\left(\theta_{1}, \theta_{2}, \theta_{3}\right)$ where $\theta_{1}, \theta_{2}$ $\theta_{3} \in \mathrm{R}$ and its membership function $\mu_{\tilde{\theta}}(\mathrm{x})$ is defined as:

$\mu_{\tilde{\theta}}(\mathrm{x})=\left\{\begin{array}{cl}\frac{\mathrm{x}-\theta_{1}}{\theta_{2}-\theta_{1}} & , \theta_{1} \leq \mathrm{x} \leq \theta_{2}, \\ \frac{\mathrm{x}-\theta_{3}}{\theta_{2}-\theta_{3}} & , \theta_{2} \leq \mathrm{x} \leq \theta_{3}, \\ 0 & \text { otherwise. }\end{array}\right.$

\subsection{Definition $^{[9]}$}

Let $\tilde{\theta}=\left(\theta_{1}, \theta_{2}, \theta_{3}\right)$ and $\tilde{\beta}=\left(\beta_{1}, \beta_{2}, \beta_{3}\right)$ are two triangular fuzzy numbers, then the basic arithmetic operations will be defined as follows:

(i) Addition:

$$
\tilde{\theta} \oplus \tilde{\beta}=\left(\theta_{1}+\beta_{1}, \theta_{2}+\beta_{2}, \theta_{3}+\beta_{3}\right) .
$$

(ii) Subtraction:

$$
\tilde{\theta} \Theta \tilde{\beta}=\left(\theta_{1}-\beta_{3}, \theta_{2}-\beta_{2}, \theta_{3}-\beta_{1}\right) .
$$

(iii) Scalar multiplication

$$
\begin{array}{ll}
\mathrm{k} \tilde{\theta}=\left(\mathrm{k} \theta_{1}, \mathrm{k} \theta_{2}, \mathrm{k} \theta_{3}\right), & \text { if } \mathrm{k} \geq 0, \\
\mathrm{k} \tilde{\theta}=\left(\mathrm{k} \theta_{3}, \mathrm{k} \theta_{2}, \mathrm{k} \theta_{1}\right), & \text { if } \mathrm{k}<0 .
\end{array}
$$

(iv) Multiplication:

$$
\begin{aligned}
& \tilde{\theta} \otimes \tilde{\beta}=\left(\theta_{1} \beta_{1}, \theta_{2} \beta_{2}, \theta_{3} \beta_{3}\right), \theta_{1} \geq 0, \\
& \tilde{\theta} \otimes \tilde{\beta}=\left(\theta_{1} \beta_{3}, \theta_{2} \beta_{2}, \theta_{3} \beta_{3}\right), \theta_{1}<0, \theta_{3} \geq 0, \\
& \tilde{\theta} \otimes \tilde{\beta}=\left(\theta_{1} \beta_{3}, \theta_{2} \beta_{2}, \theta_{3} \beta_{1}\right), \theta_{3}<0 .
\end{aligned}
$$

Let the parameters $\tilde{\mathrm{F}}_{\mathrm{i}}, \tilde{\mathrm{x}}_{\mathrm{j}}, \tilde{\mathrm{c}}_{\mathrm{ij}}, \tilde{\mathrm{a}}_{\mathrm{rj}}$ and $\tilde{b_{r}}$, $(i=1,2, \ldots, m),(j=1,2, \ldots, n),(r=1,2, \ldots, k) \quad$ be the triangular fuzzy numbers $\left(u_{i 1}, u_{i 2}, u_{i 3}\right)$, $\left(x_{j}, y_{j}, z_{j}\right),\left(r_{i j}, s_{i j}, t_{i j}\right),\left(a_{r j}, b_{r j}, c_{r j}\right)$ and $\left(p_{r}, q_{r}, h_{r}\right)$ respectively. Then the Problem (1)-(2) can be rewritten for $\mathrm{i}^{\text {th }}$ level in the following form:

$$
\begin{gathered}
{\left[i^{\text {th }} \text { level }\right]: \underset{\left(\mathrm{x}_{\mathrm{i}}, \mathrm{y}_{\mathrm{i}}, \mathrm{z}_{\mathrm{i}}\right)}{\max }\left(\mathrm{u}_{\mathrm{i} 1}, \mathrm{u}_{\mathrm{i} 2}, \mathrm{u}_{\mathrm{i} 3}\right)=\sum_{\mathrm{j}=1}^{\mathrm{n}}\left(\mathrm{r}_{\mathrm{ij}}, \mathrm{s}_{\mathrm{ij}}, \mathrm{t}_{\mathrm{ij}}\right) \otimes\left(\mathrm{x}_{\mathrm{j}}, \mathrm{y}_{\mathrm{j}}, \mathrm{z}_{\mathrm{j}}\right),} \\
(\mathrm{i}=1,2, \ldots, \mathrm{m}), \\
\text { where }\left(\mathrm{x}_{\mathrm{j}}, \mathrm{y}_{\mathrm{j}}, \mathrm{z}_{\mathrm{j}}\right) \operatorname{solves}(\mathrm{j}=\mathrm{i}+1, \ldots, \mathrm{n}),
\end{gathered}
$$

subject to

$$
\begin{aligned}
& \sum_{j=1}^{n}\left(a_{r j}, b_{r j}, c_{r j}\right) \otimes\left(x_{j}, y_{j}, z_{j}\right) \leq\left(p_{r}, q_{r}, h_{r}\right), \\
& (r=1,2, \ldots, k), \\
& x_{j}, y_{j}, z_{j} \geq 0,(j=1,2, \ldots, n) .
\end{aligned}
$$

By using the arithmetic operations which obtained in Definition 2.2, then Problem (4)-(5) is decomposed into the following form:

$$
\begin{aligned}
& {\left[{ }^{\text {th }} \text { level }\right] \text { : }} \\
& \max _{\mathrm{x}_{i}} u_{i 1}=\sum_{j=1}^{n} \text { lower value of }\left(\left(r_{i j}, s_{i j}, t_{i j}\right) \otimes\left(x_{j}, y_{j}, z_{j}\right)\right),(i=1,2, \ldots, m) \text {, } \\
& \max _{y_{i}} u_{i 2}=\sum_{j=1}^{n} \text { middle value of }\left(\left(r_{i j}, s_{i j}, t_{i j}\right) \otimes\left(x_{j}, y_{j}, z_{j}\right)\right),(i=1,2, \ldots, m) \\
& \max _{z_{i}} u_{i 3}=\sum_{j=1}^{n} \text { upper value of }\left(\left(r_{i j}, s_{i j}, t_{i j}\right) \otimes\left(x_{j}, y_{j}, z_{j}\right)\right),(i=1,2, \ldots, m) \text {, } \\
& \text { where }\left(\mathrm{x}_{\mathrm{j}}, \mathrm{y}_{\mathrm{j}}, \mathrm{z}_{\mathrm{j}}\right) \text { solves }(\mathrm{j}=\mathrm{i}+1, \ldots, \mathrm{n}) \text {. } \\
& \text { subject to } \\
& G=\left\{\sum_{j=1}^{n} \text { lower value of }\left(\left(a_{r j}, b_{r j}, c_{r j}\right) \otimes\left(x_{j}, y_{j}, z_{j}\right)\right) \leq p_{r}, \quad(r=1,2, \ldots, k)\right. \\
& \sum_{\mathrm{j}=1}^{\mathrm{n}} \text { middle value of }\left(\left(\mathrm{a}_{\mathrm{rj}}, \mathrm{b}_{\mathrm{rj}}, \mathrm{c}_{\mathrm{rj}}\right) \otimes\left(\mathrm{x}_{\mathrm{j}}, \mathrm{y}_{\mathrm{j}}, \mathrm{z}_{\mathrm{j}}\right)\right) \leq \mathrm{q}_{\mathrm{r}},(\mathrm{r}=1,2, \ldots, \mathrm{k}) \text {, } \\
& \sum_{j=1}^{n} \text { upper value of }\left(\left(a_{r j}, b_{r j}, c_{r j}\right) \otimes\left(x_{j}, y_{j}, z_{j}\right)\right) \leq h_{r},(r=1,2, \ldots, k) \text {, } \\
& \left.\mathrm{x}_{\mathrm{j}}, \mathrm{y}_{\mathrm{j}}, \mathrm{z}_{\mathrm{j}} \geq 0(\mathrm{j}=1,2, \ldots, \mathrm{n})\right\} \text {. }
\end{aligned}
$$




\section{BOUND AND DECOMPOSITION METHOD FOR TREATING FFMLLP PROBLEM}

To find the crisp model for the (FFMLLP) problem (6)-(7), the bound and decomposition method ${ }^{[9]}$ was used. It decomposed the Problem (6)-(7) into three crisp multi-level linear programming (MLLP) problems with bounded variables constraints where these problems are solved separately and by using its optimal solutions.

Construct the decomposed problems for the $\mathrm{i}^{\text {th }}$ level as follows:

(i) The middle multi-level problem (MMLP) of the $i^{\text {th }}$ level:

$(\mathrm{MLLPP})_{\mathrm{M}}$

$\max _{y_{i}} u_{i 2}=\sum_{j=1}^{n}$ middle value of $\left(\left(r_{i j}, s_{i j}, t_{i j}\right) \otimes\left(x_{j}, y_{j}, z_{j}\right)\right),(i=1,2, \ldots, m)$,

where $y_{j}$ solves

$(j=i+1, \ldots, n)$,

subject to

$$
\begin{gathered}
\sum_{j=1}^{n} \text { middle value of }\left(\left(a_{r j}, b_{r j}, c_{r j}\right) \otimes\left(x_{j}, y_{j}, z_{j}\right)\right) \leq q_{r},(r=1,2, \ldots, k), \\
x_{j}, y_{j}, z_{j} \geq,(j=1,2, \ldots, n) .
\end{gathered}
$$

(ii)

The upper multi-level problem (UMLP) of the $i^{\text {th }}$ level:

$(\mathrm{MLLPP})_{\mathrm{U}}$ :

$\max _{\mathrm{z}_{\mathrm{i}}} \mathrm{u}_{\mathrm{i} 3}=\sum_{\mathrm{j}=1}^{\mathrm{n}}$ upper value of $\left(\left(\mathrm{r}_{\mathrm{ij}}, \mathrm{s}_{\mathrm{ij}}, \mathrm{t}_{\mathrm{ij}}\right) \otimes\left(\mathrm{x}_{\mathrm{j}}, \mathrm{y}_{\mathrm{j}}, \mathrm{z}_{\mathrm{j}}\right)\right),(\mathrm{i}=1,2, \ldots, \mathrm{m})$,

where $z_{j}$ solves $(j=i+1, \ldots, n)$,

subject to

$$
\begin{gathered}
\sum_{j=1}^{n} \text { upper value of }\left(\left(a_{r j}, b_{r j}, c_{r j}\right) \otimes\left(x_{j}, y_{j}, z_{j}\right)\right) \leq h_{r}(r=1,2, \ldots, k) \\
\sum_{j=1}^{n} \text { upper value of }\left(\left(r_{i j}, s_{i j}, t_{i j}\right) \otimes\left(x_{j}, y_{j}, z_{j}\right)\right) \geq u_{i 2}^{*}(i=1,2, \ldots, m) \\
z_{j} \geq y_{j}(j=1,2, \ldots, n) \\
x_{j}, y_{j}, z_{j} \geq 0(j=1,2, \ldots, n)
\end{gathered}
$$

(iii) The lower multi-level problem (LMLP) of the $i^{\text {th }}$ level:

$(\text { MLLPP) })_{\mathrm{L}}$

$\max _{x_{i}} u_{i 1}=\sum_{j=1}^{n}$ lower value of $\left(\left(r_{i j}, s_{i j}, t_{i j}\right) \otimes\left(x_{j}, y_{j}, z_{j}\right)\right),(i=1,2, \ldots, m)$,

where $x_{j}$ solves $(j=i+1, \ldots, n)$,

subject to

$$
\begin{gathered}
\sum_{j=1}^{n} \text { lower value of }\left(\left(a_{r j}, b_{r j}, c_{r j}\right) \otimes\left(x_{j}, y_{j}, z_{j}\right)\right) \leq p_{r}(r=1,2, \ldots, k), \\
\sum_{j=1}^{n} \text { lower value of }\left(\left(r_{i j}, s_{i j}, t_{i j}\right) \otimes\left(x_{j}, y_{j}, z_{j}\right)\right) \leq u_{i 2}^{*}(i=1,2, \ldots, m), \\
x_{j} \leq y_{j}(j=1,2, \ldots, n), \\
x_{j}, y_{j}, z_{j} \geq 0(j=1,2, \ldots, n) .
\end{gathered}
$$

where $u_{i 2}^{*},(i=1,2, \ldots, m)$ are the optimal values of the objective function in the middle multi-level problem (8) for the $\mathrm{i}^{\text {th }}$ level.

\subsection{Definition ${ }^{[9]}$}

If $x_{j M}^{o}, \quad x_{j U}^{o}$ and $\quad x_{j L}^{o}(j=1,2, \ldots, n)$ are the optimal solutions for every level of the Problems $\left(\right.$ MLLPP) ${ }_{M}$ $(\text { MLLPP })_{\mathrm{U}}$ and $(\text { MLLPP })_{\mathrm{L}}$ ((8)-(10)) respectively, then $\tilde{x}_{j}^{o}=\left(x_{j L}^{o}, x_{j M}^{o}, x_{j U}^{o}\right),(j=1,2, \ldots, n)$ are the optimal fuzzy solutions for every level in the Problem (4)-(5).

\section{FUZZY DECISION APPROACH FOR MLLP PROBLEM}

The solution of MLLP problem by adopting is based on the multi-planner Stakelberg ${ }^{[16][17]}$, and the fuzzy decision model [18]. Firstly, find an acceptable satisfactory solution to the FLDM and then give the decision variables and goals of the FLDM with some leeway to the SLDM for him/her to seek the satisfactory solution. Then the SLDM give the decision variables and goals with some leeway to the TLDM for $\mathrm{him} /$ her to seek the satisfactory solution. And so on to the $\mathrm{m}^{\text {th }}$ level and to set the solution which is closest to the satisfactory solution of the FLDM,

Build the membership functions of the fuzzy set theory [18] for the $\mathrm{i}^{\text {th }}$ LDM as follows:

$\mu\left(\tilde{\mathrm{F}}_{\mathrm{i}}\right)= \begin{cases}1 & \text {,if } \tilde{\mathrm{F}}_{\mathrm{i}}>\tilde{\mathrm{F}}_{\mathrm{i}}^{*}, \\ \frac{\tilde{\mathrm{F}}_{\mathrm{i}}-\tilde{\mathrm{F}}_{\mathrm{i}}^{-}}{\tilde{\mathrm{F}}_{\mathrm{i}}^{*}-\tilde{\mathrm{F}}_{\mathrm{i}}^{-}} & , \text {if } \tilde{\mathrm{F}}_{\mathrm{i}}^{-} \leq \tilde{\mathrm{F}}_{\mathrm{i}} \leq \tilde{\mathrm{F}}_{\mathrm{i}}^{*},(\mathrm{i}=1,2, \ldots, \mathrm{m}), \\ 0 & \text {,if } \tilde{\mathrm{F}}_{\mathrm{i}}^{-} \geq \tilde{\mathrm{F}}_{\mathrm{i}} .\end{cases}$

where $\tilde{\mathrm{F}}_{\mathrm{i}}^{*}$ and $\tilde{\mathrm{F}}_{\mathrm{i}}^{-}(\mathrm{i}=1,2, \ldots, \mathrm{m})$ are the individual best fuzzy solutions and the individual worst fuzzy solutions respectively of Problems (6)-(7). Such that

$\tilde{\mathrm{F}}_{\mathrm{i}}^{*}=\max _{\tilde{\mathrm{x}} \in \mathrm{G}} \mathrm{F}_{\mathrm{i}}(\tilde{\mathrm{x}}), \tilde{\mathrm{F}}_{\mathrm{i}}^{-}=\min _{\tilde{\mathrm{x}} \in \mathrm{G}} \mathrm{F}_{\mathrm{i}}(\tilde{\mathrm{x}}),(\mathrm{i}=1,2, \ldots, \mathrm{m})$.

Find the fuzzy solutions of the $\mathrm{i}^{\text {th }}$ LDM problem by solving the following Tchebycheff problem ${ }^{[17][19]}$ :

$\max \tilde{\lambda}_{i},(i=1,2, \ldots, m)$,

subject to

$$
\begin{aligned}
& \mu\left(\tilde{\mathrm{F}}_{\mathrm{i}}\right) \geq \tilde{\lambda}_{\mathrm{i}},(\mathrm{i}=1,2, \ldots, \mathrm{m}), \\
& \tilde{\mathrm{x}} \in \mathrm{G}, \quad \tilde{\lambda}_{\mathrm{i}} \in[0,1], \quad(\mathrm{i}=1,2, \ldots, \mathrm{m}) .
\end{aligned}
$$

Let $\tilde{\lambda}_{i}=\left(\lambda_{i 1}, \lambda_{i 2}, \lambda_{i 3}\right),(i=1,2, \ldots, m)$, then solve the three decomposed Tchebycheff problems for all decision makers problem. Then the fuzzy solutions are determined $\tilde{\lambda}_{i}^{\mathrm{o}}, \tilde{\mathrm{x}}_{\mathrm{j}}^{\mathrm{i}}, \tilde{\mathrm{F}}_{\mathrm{i}}\left(\tilde{\mathrm{x}}_{\mathrm{j}}^{\mathrm{i}}\right),(\mathrm{i}=1,2, \ldots, \mathrm{m}),(\mathrm{j}=1,2, \ldots, \mathrm{n})$ at each level. 


\subsection{Definition ${ }^{[16]}$}

For any

$\tilde{x}_{i}\left(\tilde{x}_{i} \in G_{i}=\left\{\tilde{x}_{i},(i=1,2, \ldots, m-1) \mid\left(\tilde{x}_{1}, \tilde{x}_{2}, \ldots, \tilde{x}_{n}\right) \in G\right\}\right)$

given by the $\mathrm{i}^{\text {th }}$ LDM, $(\mathrm{i}=1,2, \ldots, \mathrm{m}-1)$. If the decision making variables

$\left(\tilde{x}_{k} \in G_{m}=\left\{\tilde{x}_{k},(k=m, m+1, \ldots, n) \mid\left(\tilde{x}_{1}, \tilde{x}_{2}, \ldots, \tilde{x}_{n}\right) \in G\right\}\right)$

$\tilde{\mathrm{x}}_{\mathrm{k}},(\mathrm{k}=\mathrm{m}, \mathrm{m}+1, \ldots, \mathrm{n})$, is the fuzzy optimal solutions of

the $\mathrm{m}^{\text {th }} \mathrm{LDM}$, then $\left(\tilde{\mathrm{x}}_{1}, \tilde{\mathrm{x}}_{2}, \ldots, \tilde{\mathrm{x}}_{\mathrm{n}}\right)$ is the feasible fuzzy

solution of FFMLLP problem.

Finally, in order to generate the satisfactory fuzzy solutions,

which are also optimal fuzzy solutions with overall

satisfaction for all DMs, solve the following Tchebycheff problem:

$\max \tilde{\delta}$,

subject to

$$
\begin{aligned}
& \tilde{\mathrm{x}} \in \mathrm{G} \\
& \frac{\left[\left(\tilde{\mathrm{x}}_{\mathrm{i}}^{\mathrm{i}}+\tilde{\mathrm{T}}_{\mathrm{i}}\right)-\tilde{\mathrm{x}}_{\mathrm{i}}\right]}{\tilde{\mathrm{T}}_{\mathrm{i}}} \geq \tilde{\delta} \mathrm{I},(\mathrm{i}=1,2, \ldots, \mathrm{m}-1), \\
& \frac{\left[\tilde{\mathrm{x}}_{\mathrm{i}}-\left(\tilde{\mathrm{x}}_{\mathrm{i}}^{\mathrm{i}}-\tilde{\mathrm{T}}_{\mathrm{i}}\right)\right]}{\tilde{\mathrm{T}}_{\mathrm{i}}} \geq \tilde{\delta} \mathrm{I},(\mathrm{i}=1,2, \ldots, \mathrm{m}-1), \\
& \mu_{\tilde{\mathrm{F}}_{\mathrm{i}}}^{\prime}\left(\tilde{\mathrm{F}}_{\mathrm{i}}\right) \geq \tilde{\delta},(\mathrm{i}=1,2, \ldots, \mathrm{m}), \\
& \tilde{\mathrm{T}}_{\mathrm{i}}>0,(\mathrm{i}=1,2, \ldots, \mathrm{m}-1), \\
& \tilde{\delta} \in[0,1] .
\end{aligned}
$$

where $\tilde{\delta}$ is the overall satisfaction, and $I$ is the column vector with all elements equal to $1 \mathrm{~s}$. And $(i=1,2, \ldots, \mathrm{m}-1)$

$\tilde{\mathrm{T}}_{\mathrm{i}}$, are the maximum tolerances of the decision variables

$\tilde{x}_{\mathbf{i}}(\mathrm{i}=1,2, \ldots, \mathrm{m}-1)$. The membership functions

$\mu_{\tilde{F}_{i}}^{\prime}\left(\tilde{F}_{i}\right),(i=1,2, \ldots, m)$ of the $i^{\text {th }} \operatorname{LDM},(i=1,2, \ldots, m)$

are stated as follows:

$$
\mu_{\tilde{F}_{i}}^{\prime}\left(\tilde{\mathrm{F}}_{\mathrm{i}}(\tilde{\mathrm{x}})\right)= \begin{cases}1 & , \text { if } \tilde{\mathrm{F}}_{\mathrm{i}}\left(\tilde{\mathrm{x}}_{)}>\tilde{\mathrm{F}}_{\mathrm{i}}\left(\tilde{\mathrm{x}}_{\mathrm{j}}^{\mathrm{i}}\right),\right. \\ \frac{\tilde{\mathrm{F}}_{\mathrm{i}}(\tilde{\mathrm{x}})-\tilde{\mathrm{F}}_{\mathrm{i}}^{\prime}}{\tilde{\mathrm{F}}_{\mathrm{i}}\left(\tilde{\mathrm{x}}_{\mathrm{j}}^{\mathrm{i}}\right)-\tilde{\mathrm{F}}_{\mathrm{i}}^{\prime}} & , \text { if } \tilde{\mathrm{F}}_{\mathrm{i}}^{\prime} \leq \tilde{\mathrm{F}}_{\mathrm{i}}(\tilde{\mathrm{x}}) \leq \tilde{\mathrm{F}}_{\mathrm{i}}\left(\tilde{\mathrm{x}}_{\mathrm{j}}^{\mathrm{i}}\right),(\mathrm{i}=1,2, \ldots, \mathrm{m}), \\ 0 & , \text { if } \tilde{\mathrm{F}}_{\mathrm{i}}\left(\tilde{\mathrm{x}}_{\mathrm{x}}\right) \leq \tilde{\mathrm{F}}_{\mathrm{i}}^{\prime} .\end{cases}
$$

$$
\text { such that } \quad \tilde{\mathrm{F}}_{\mathrm{i}}^{\prime}=\tilde{\mathrm{F}}_{\mathrm{i}}\left(\mathrm{x}_{\mathrm{j}}^{\mathrm{i}+1}\right),(\mathrm{i}=1,2, \ldots, \mathrm{m}-1) \text {, }
$$$$
(j=1,2, \ldots, n) \text { and } \tilde{F}_{m}^{\prime}=\tilde{F}_{m}\left(x_{j}^{m-1}\right),(j=1,2, \ldots, n) \text {. }
$$

Let

$$
\tilde{\delta}=\left(\delta_{1}, \delta_{2}, \delta_{3}\right) \text { and } \tilde{T}_{i}=\left(T_{i 1}, T_{i 2}, T_{i 3}\right),(i=1,2, \ldots, m-1)
$$

and. By solving the three decomposition problems for each level, if the FLDM is satisfied with solution then satisfactory solution is reached. Otherwise, he/she should provide new membership function for the control variables and objectives to the $\mathrm{i}^{\text {th }} \mathrm{LDM},(\mathrm{i}=1,2, \ldots, \mathrm{m})$ until a satisfactory solution is reached.

\section{AN ALGORITHM FOR SOLVING FFMLLP PROBLEM}

A solution algorithm to solve the (FFMLLP) problem is described in a series of steps. This algorithm uses bound and decomposition method for solving a (FFLP) problem and uses Fuzzy programming approach to get a compromised solution for the problem under consideration.

The suggested algorithm can be summarized in the following manner:

Step 1: Formulate the FFMLLP problem go to step 2.

Step 2: Let all fuzzy variables and fuzzy coefficients are triangular fuzzy numbers.

Step 3: Convert the FFMLLP problem as problem (4)-(5).

Step 4: Set $i=1$.

Step 5: Convert the I-LDM problem (4)-(5) into the nonfuzzy model as problem (6)-(7) by using the arithmetic operations on fully fuzzy and by the bound and decomposition method ${ }^{[9]}$.

Step 6: Calculate the individual best and worst solutions for the decomposed problems of the I-LDM problem.

Step 7: Build the membership function of the I-LDM problem as problem (11).

Step 8: Use the arithmetic operations on fully fuzzy and by the bound and decomposition method ${ }^{[9]}$ to find the fuzzy solution of the Tchebycheff problem of the the I-LDM problem as problem (13).

Step 9: If $i=n$, go to step 10 , otherwise, $i=i+1$, then go to step 5.

Step 10: Set $i=1$.

Step 11: Define the value of the control decision variables and the maximum tolerance for the I-LDM.

Step 12: Build the membership function of the I-LDM as problem (15).

Step 13: If $i=n-1, i=i+1$, then go to step 14 , otherwise, $i=i+1$, then go to step 11 .

Step 14: Build the membership function of the the I-LDM as problem (15).

Step 15: Formulate a Tchebycheff problem for all decision makers problem as (14).

Step 16: Use the arithmetic operations by the bound and decomposition method to find the compromise solution of the Tchebycheff problem for all decision makers.

Step 17: If $\delta<0.5$, where $\delta$ is the overall satisfaction , then increase the tolerance and go to step 11 , otherwise go to step 18.

Step 18: The compromise solution of the problem is obtained and $\delta$ is overall satisfaction for all decision-makers.

\section{AFLOW CHART FOR SOLVING FFMLLPP}




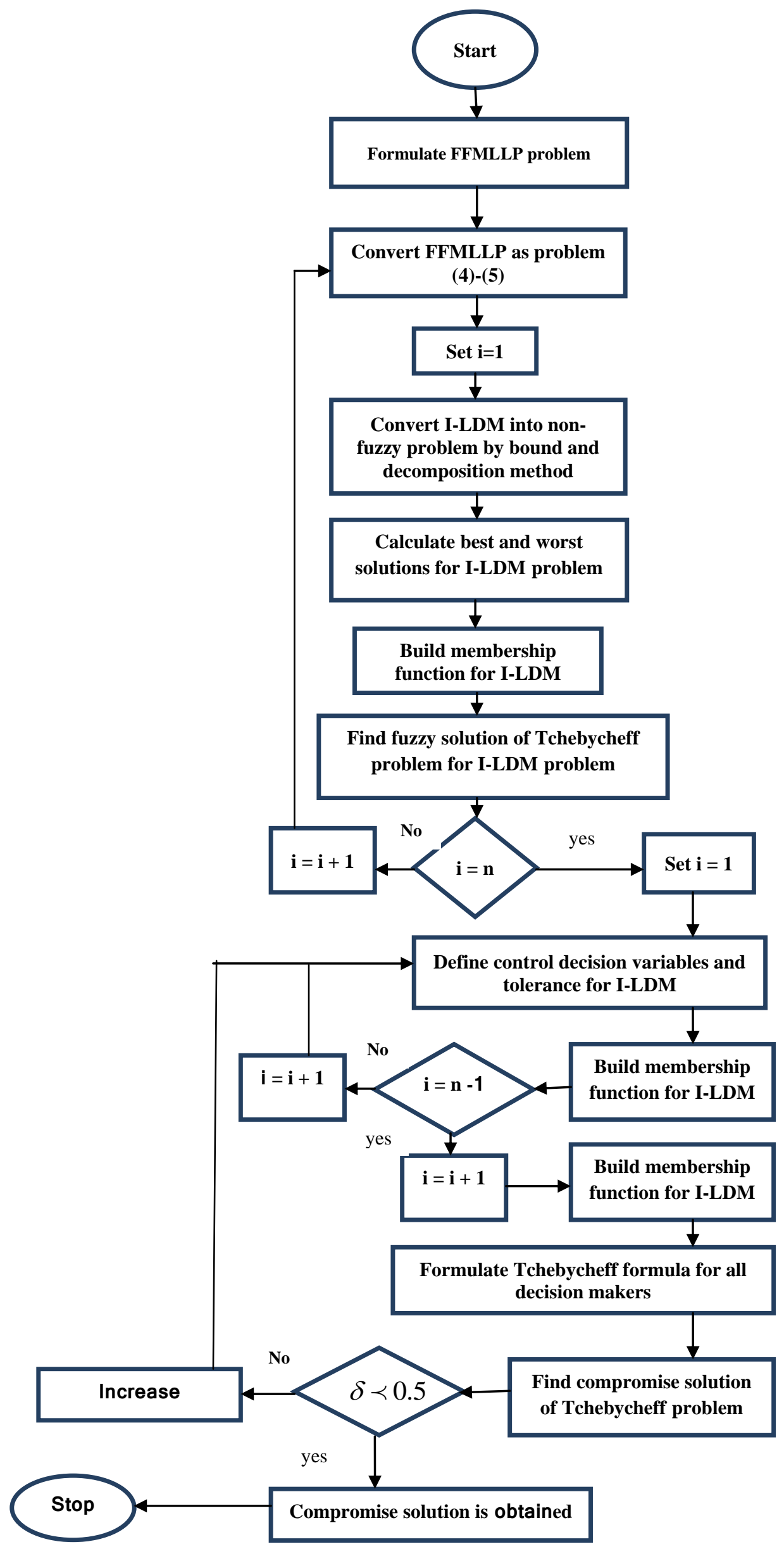




\section{NUMERICAL EXAMPLE}

Consider the following example of fully fuzzy three-level linear programming (FFTLLP) problem:

$\left[2^{\text {nd }}\right.$ level $]$ :

$\max _{\tilde{\mathrm{x}}_{2}} \tilde{\mathrm{F}}_{2}=(4,7,9) \tilde{\mathrm{x}}_{1}+(6,10,12) \tilde{\mathrm{x}}_{2}+(3,8,11) \tilde{\mathrm{x}}_{3}$,

where $\tilde{\mathrm{x}}_{3}$ solves,

$\left[3^{\text {rd }}\right.$ level $]$ :

$\max _{\tilde{\mathrm{x}}_{3}} \tilde{\mathrm{F}}_{3}=(7,10,12) \tilde{\mathrm{x}}_{1}+(5,9,11) \tilde{\mathrm{x}}_{2}+(10,13,16) \tilde{\mathrm{x}}_{3}$,

subject to

$(1,2,3) \tilde{\mathrm{x}}_{1}+(5,6,8) \tilde{\mathrm{x}}_{2}+(3,5,9) \tilde{\mathrm{x}}_{3} \leq(20,25,50)$,

$(4,8,11) \tilde{\mathrm{x}}_{1}+(1,3,6) \tilde{\mathrm{x}}_{2}+(2,3,4) \tilde{\mathrm{x}}_{3} \leq(18,23,40)$,

$(5,9,10) \tilde{x}_{1}+(2,4,7) \tilde{x}_{2}+(1,2,6) \tilde{x}_{3} \leq(27,32,55)$,

$$
\tilde{\mathrm{x}}_{1}, \tilde{\mathrm{x}}_{2}, \tilde{\mathrm{x}}_{3} \geq 0 \text {. }
$$

Let

$\tilde{\mathrm{x}}_{1}=\left(\mathrm{x}_{1}, \mathrm{y}_{1}, \mathrm{z}_{1}\right), \tilde{\mathrm{x}}_{2}=\left(\mathrm{x}_{2}, \mathrm{y}_{2}, \mathrm{z}_{2}\right), \tilde{\mathrm{x}}_{3}=\left(\mathrm{x}_{3}, \mathrm{y}_{3}, \mathrm{z}_{3}\right)$,

$\tilde{\mathrm{F}}_{1}=\left(\mathrm{u}_{1}, \mathrm{u}_{2}, \mathrm{u}_{3}\right), \tilde{\mathrm{F}}_{2}=\left(\mathrm{u}_{4}, \mathrm{u}_{5}, \mathrm{u}_{6}\right)$

and $\tilde{\mathrm{F}}_{3}=\left(\mathrm{u}_{7}, \mathrm{u}_{8}, \mathrm{u}_{9}\right)$, then you have:

$\left[1^{\text {st }}\right.$ level $]$ :

$\max _{\left(\mathrm{x}_{1}, \mathrm{y}_{1}, \mathrm{z}_{1}\right)}\left(\mathrm{u}_{1}, \mathrm{u}_{2}, \mathrm{u}_{3}\right)=$

$(8,11,15)\left(\mathrm{x}_{1}, \mathrm{y}_{1}, \mathrm{z}_{1}\right)+(1,3,7)\left(\mathrm{x}_{2}, \mathrm{y}_{2}, \mathrm{z}_{2}\right)+(2,5,8)\left(\mathrm{x}_{3}, \mathrm{y}_{3}, \mathrm{z}_{3}\right)$,

where $\left(\mathrm{x}_{2}, \mathrm{y}_{2}, \mathrm{z}_{2}\right),\left(\mathrm{x}_{3}, \mathrm{y}_{3}, \mathrm{z}_{3}\right)$ solves,

$\left[2^{\text {nd }}\right.$ level $]$ :

$\max _{\left(\mathrm{x}_{2}, \mathrm{y}_{2}, \mathrm{z}_{2}\right)}\left(\mathrm{u}_{4}, \mathrm{u}_{5}, \mathrm{u}_{6}\right)=$

$(4,7,9)\left(\mathrm{x}_{1}, \mathrm{y}_{1}, \mathrm{z}_{1}\right)+(6,10,12)\left(\mathrm{x}_{2}, \mathrm{y}_{2}, \mathrm{z}_{2}\right)+(3,8,11)\left(\mathrm{x}_{3}, \mathrm{y}_{3}, \mathrm{z}_{3}\right)$,

where $\left(\mathrm{x}_{3}, \mathrm{y}_{3}, \mathrm{z}_{3}\right)$ solves,

$\left[3^{\text {rd }}\right.$ level $]$ :

$\max _{\left(\mathrm{x}_{3}, \mathrm{y}_{3}, \mathrm{z}_{3}\right)}\left(\mathrm{u}_{7}, \mathrm{u}_{8}, \mathrm{u}_{9}\right)=$

$(7,10,12)\left(\mathrm{x}_{1}, \mathrm{y}_{1}, \mathrm{z}_{1}\right)+(5,9,11)\left(\mathrm{x}_{2}, \mathrm{y}_{2}, \mathrm{z}_{2}\right)+(10,13,16)\left(\mathrm{x}_{3}, \mathrm{y}_{3}, \mathrm{z}_{3}\right)$,

subject to

$(1,2,3)\left(\mathrm{x}_{1}, \mathrm{y}_{1}, \mathrm{z}_{1}\right)+(5,6,8)\left(\mathrm{x}_{2}, \mathrm{y}_{2}, \mathrm{z}_{2}\right)+(3,5,9)\left(\mathrm{x}_{3}, \mathrm{y}_{3}, \mathrm{z}_{3}\right) \leq(20,25,50)$,

$(4,8,11)\left(\mathrm{x}_{1}, \mathrm{y}_{1}, \mathrm{z}_{1}\right)+(1,3,6)\left(\mathrm{x}_{2}, \mathrm{y}_{2}, \mathrm{z}_{2}\right)+(2,3,4)\left(\mathrm{x}_{3}, \mathrm{y}_{3}, \mathrm{z}_{3}\right) \leq(18,23,40)$,

$(5,9,10)\left(\mathrm{x}_{1}, \mathrm{y}_{1}, \mathrm{z}_{1}\right)+(2,4,7)\left(\mathrm{x}_{2}, \mathrm{y}_{2}, \mathrm{z}_{2}\right)+(1,2,6)\left(\mathrm{x}_{3}, \mathrm{y}_{3}, \mathrm{z}_{3}\right) \leq(27,32,55)$,

$\mathrm{x}_{1}, \mathrm{x}_{2}, \mathrm{x}_{3}, \mathrm{y}_{1}, \mathrm{y}_{2}, \mathrm{y}_{3}, \mathrm{z}_{1}, \mathrm{z}_{2}, \mathrm{z}_{3} \geq 0$.

By using the arithmetic operations in Definition 2.2 and the bound and decomposition method[9], the decomposition became non-fuzzy three- level linear programming problem as follows:

$$
\begin{aligned}
& {\left[1^{\text {st }} \text { level }\right] \text { : }} \\
& \max _{\mathrm{x}_{1}} \mathrm{u}_{1}=8 \mathrm{x}_{1}+\mathrm{x}_{2}+2 \mathrm{x}_{3} \text {, } \\
& \max _{\mathrm{y}_{1}} \mathrm{u}_{2}=11 \mathrm{y}_{1}+3 \mathrm{y}_{2}+5 \mathrm{y}_{3} \text {, } \\
& \max _{\mathrm{z}_{1}} \mathrm{u}_{3}=15 \mathrm{z}_{1}+7 \mathrm{z}_{2}+8 \mathrm{z}_{3} \text {, } \\
& \text { where }\left(\mathrm{x}_{2}, \mathrm{y}_{2}, \mathrm{z}_{2}\right),\left(\mathrm{x}_{3}, \mathrm{y}_{3}, \mathrm{z}_{3}\right) \text { solves, } \\
& {\left[2^{\text {nd }} \text { level }\right] \text { : }} \\
& \max _{\mathrm{x}_{2}} \mathrm{u}_{4}=4 \mathrm{x}_{1}+6 \mathrm{x}_{2}+3 \mathrm{x}_{3} \text {, } \\
& \max _{\mathrm{y}_{2}} \mathrm{u}_{5}=7 \mathrm{y}_{1}+10 \mathrm{y}_{2}+8 \mathrm{y}_{3} \text {, } \\
& \max _{\mathrm{z}_{2}} \mathrm{u}_{6}=9 \mathrm{z}_{1}+12 \mathrm{z}_{2}+11 \mathrm{z}_{3} \text {, } \\
& \text { where }\left(\mathrm{x}_{3}, \mathrm{y}_{3}, \mathrm{z}_{3}\right) \text { solves, } \\
& {\left[3^{\text {rd }} \text { level }\right] \text { : }} \\
& \max _{\mathrm{x}_{3}} \mathrm{u}_{7}=7 \mathrm{x}_{1}+5 \mathrm{x}_{2}+10 \mathrm{x}_{3} \text {, } \\
& \max _{\mathrm{y}_{3}} \mathrm{u}_{8}=10 \mathrm{y}_{1}+9 \mathrm{y}_{2}+13 \mathrm{y}_{3} \text {, } \\
& \mathrm{y}_{3} \\
& \max _{\mathrm{z}_{3}} \mathrm{u}_{9}=12 \mathrm{z}_{1}+11 \mathrm{z}_{2}+16 \mathrm{z}_{3} \\
& \mathrm{G}=\left\{\mathrm{x}_{1}+5 \mathrm{x}_{2}+3 \mathrm{x}_{3} £ 20,\right. \\
& 4 \mathrm{x}_{1}+\mathrm{x}_{2}+2 \mathrm{x}_{3} £ 18 \\
& 5 \mathrm{x}_{1}+2 \mathrm{x}_{2}+\mathrm{x}_{3} £ 27 \text {, } \\
& 2 \mathrm{y}_{1}+6 \mathrm{y}_{2}+5 \mathrm{y}_{3} £ 25 \text {, } \\
& 8 \mathrm{y}_{1}+3 \mathrm{y}_{2}+3 \mathrm{y}_{3} £ 23 \\
& 9 \mathrm{y}_{1}+4 \mathrm{y}_{2}+2 \mathrm{y}_{3} £ 32 \text {, } \\
& 3 \mathrm{z}_{1}+8 \mathrm{z}_{2}+9 \mathrm{z}_{3} £ 50 \\
& 11 z_{1}+6 z_{2}+4 z_{3} £ 40, \\
& 10 \mathrm{z}_{1}+7 \mathrm{z}_{2}+6 \mathrm{z}_{3} £ 55 \text {, } \\
& \left.\mathrm{x}_{1}, \mathrm{x}_{2}, \mathrm{x}_{3}, \mathrm{y}_{1}, \mathrm{y}_{2}, \mathrm{y}_{3}, \mathrm{z}_{1}, \mathrm{z}_{2}, \mathrm{z}_{3}{ }^{30}\right\} \text {. }
\end{aligned}
$$

By applying the bound and decomposition method on the first level problem, it will be decomposed into the following three linear programming (LP) problems. Then the individual optimal fuzzy solution can be obtained by solving these problems. 
1. The middle level problem (MLP) of the first level:

$$
\begin{gathered}
(\text { MLP })^{1 \text { st }}: \max _{y_{1}} u_{2}=11 y_{1}+3 y_{2}+5 y_{3}, \\
\text { subject to } \\
2 y_{1}+6 y_{2}+5 y_{3} \leq 25 \\
8 y_{1}+3 y_{2}+3 y_{3} \leq 23 \\
9 y_{1}+4 y_{2}+2 y_{3} \leq 32 \\
y_{1}, y_{2}, y_{3} \geq 0
\end{gathered}
$$

The optimal solution $\mathrm{y}_{1}=1.176, \mathrm{y}_{2}=0, \mathrm{y}_{3}=4.529$ and $\mathrm{u}_{2}=35.588$.

2. The upper level problem (ULP) of the first level:

$(\mathrm{ULP})^{1 \mathrm{st}}: \max _{\mathrm{z}_{1}} \mathrm{u}_{3}=15 \mathrm{z}_{1}+7 \mathrm{z}_{2}+8 \mathrm{z}_{3}$,

subject to

$$
\begin{gathered}
3 z_{1}+8 z_{2}+9 z_{3} \leq 50, \\
11 z_{1}+6 z_{2}+4 z_{3} \leq 40, \\
10 z_{1}+7 z_{2}+6 z_{3} \leq 55, \\
15 z_{1}+7 z_{2}+8 z_{3} \geq 35.588, \\
z_{1} \geq 1.176 \\
z_{3} \geq 4.529 \\
z_{1}, z_{2}, z_{3} \geq 0 .
\end{gathered}
$$

The optimal solution $\mathrm{z}_{1}=1.839, \mathrm{z}_{2}=0, \mathrm{z}_{3}=4.943$ and $\mathrm{u}_{3}=67.126$.

3. The lower level problem (LLP) of the first level:

$$
\begin{gathered}
(\text { LLP })^{1 \text { st }}: \max _{\mathrm{x}_{1}} \mathrm{u}_{1}=8 \mathrm{x}_{1}+\mathrm{x}_{2}+2 \mathrm{x}_{3}, \\
\text { subject to } \\
\mathrm{x}_{1}+5 \mathrm{x}_{2}+3 \mathrm{x}_{3} \leq 20, \\
4 \mathrm{x}_{1}+\mathrm{x}_{2}+2 \mathrm{x}_{3} \leq 18, \\
5 \mathrm{x}_{1}+2 \mathrm{x}_{2}+\mathrm{x}_{3} \leq 27, \\
8 \mathrm{x}_{1}+\mathrm{x}_{2}+2 \mathrm{x}_{3} \leq 35.588 \\
\mathrm{x}_{1} \leq 1.176 \\
\mathrm{x}_{3} \leq 4.529 \\
\mathrm{x}_{1}, \mathrm{x}_{2}, \mathrm{x}_{3} \geq 0 .
\end{gathered}
$$

The optimal solution $\mathrm{x}_{1}=1.176, \mathrm{x}_{2}=1.047, \mathrm{x}_{3}=4.529$ and $\mathrm{u}_{1}=19.518$.
Similarly, do the same way on the SLDM and TLDM to have the following results:

Table 1. The individual best fuzzy solutions of the FFTLLP problem.

\begin{tabular}{|c|c|c|c|}
\hline & \multicolumn{3}{|c|}{ Individual best fuzzy solution } \\
\hline & FLDM (i=1) & SLDM (i=2) & TLDM (i=3) \\
\hline$\tilde{\mathrm{x}}_{1}^{*}$ & $(1.18,1.18,1.84)$ & $(1.5,1.5,1.5)$ & $(1.18,1.77,1.84)$ \\
\hline$\tilde{\mathrm{x}}_{2}^{*}$ & $(1.047,0,0)$ & $(3.67,3.67,3.67)$ & $(0,0,0)$ \\
\hline$\tilde{\mathrm{x}}_{3}^{*}$ & $(4.53,4.53,4.94)$ & $(0,0,0.375)$ & $(4.53,4.53,4.94)$ \\
\hline$\tilde{\mathrm{F}}_{\mathrm{i}}^{*}$ & $(19.52,35.59,67.13)$ & $(28.0,47.17,61.63)$ & $(53.52,70.65,101.15)$ \\
& & & \\
\hline
\end{tabular}

Table 2. The individual worst fuzzy solutions of the(FFTLLP) problem.

\begin{tabular}{|c|c|c|c|}
\hline & \multicolumn{3}{|c|}{ Individual worst fuzzy solution } \\
\hline & FLDM (i=1) & SLDM (i=2) & TLDM (i=3) \\
\hline$\tilde{\mathrm{x}}_{1}^{-}$ & $(0,0,1.176)$ & $(0,0,1.5)$ & $(0,0,1.176)$ \\
\hline$\tilde{\mathrm{x}}_{2}^{-}$ & $(0,0,0)$ & $(0,0,3.667)$ & $(0,0,0)$ \\
\hline$\tilde{\mathrm{x}}_{3}^{-}$ & $(0,0,4.529)$ & $(0,0,0)$ & $(0,0,4.529)$ \\
\hline$\tilde{\mathrm{F}}_{\mathrm{i}}^{-}$ & $(0,0,53.882)$ & $(0,0,57.5)$ & $(0,0,86.588)$ \\
\hline
\end{tabular}

By using (11), build the membership function $\mu\left(\tilde{F}_{i}\right),(i=1,2,3)$ for the FLDM, SLDM and TLDM. Then solve the following Tchebycheff problem for each level:

$\max \tilde{\lambda}_{i}(i=1,2,3)$,

subject to

$$
\begin{aligned}
& \mu\left(\tilde{F}_{i}\right) \geq \tilde{\lambda}_{i},(i=1,2,3), \\
& \tilde{x} \in G, .
\end{aligned}
$$

Let $\tilde{\lambda}_{i}=\left(\lambda_{i 1}, \lambda_{i 2}, \lambda_{i 3}\right),(i=1,2,3)$. Apply the arithmetic operations in Definition 2.2 and the bound and decomposition $\operatorname{method}^{[9]}$, then you get the following results: 
Table 3. The fuzzy solution of Tchebycheff problems at each level

\begin{tabular}{|c|c|c|c|c|c|}
\hline & $\tilde{\lambda}_{i}$ & $\begin{array}{c}\tilde{x}_{j}^{i} \\
(\mathrm{j}=1,2,3)\end{array}$ & $\begin{array}{c}\tilde{x}_{j}^{i} \\
(\mathrm{j}=1,2,3)\end{array}$ & $\begin{array}{c}\tilde{x}_{j}^{i} \\
(\mathrm{j}=1,2,3)\end{array}$ & $\tilde{F}_{i}\left(\tilde{x}_{j}^{i}\right)$ \\
\hline $\mathrm{i}=1$ & $(1,1,1)$ & $\left(\begin{array}{l}1.18,1.18 \\
1.84\end{array}\right)$ & $\left(\begin{array}{l}1.5,1.5, \\
1.5\end{array}\right)$ & $\left(\begin{array}{c}0,0, \\
1.18\end{array}\right)$ & $\left(\begin{array}{l}18.47 \\
35.59 \\
67.13\end{array}\right)$ \\
\hline $\mathrm{i}=2$ & $(1,1,1)$ & $(0,0,0)$ & $\left(\begin{array}{l}3.67,3.67, \\
3.67\end{array}\right)$ & $(0,0,0)$ & $\left(\begin{array}{l}29.0 \\
47.17 \\
61.63\end{array}\right)$ \\
\hline $\mathrm{i}=3$ & $(1,1,1)$ & $\left(\begin{array}{l}4.53,4.53, \\
4.94\end{array}\right)$ & $\left(\begin{array}{l}0,0, \\
0.375\end{array}\right)$ & $\left(\begin{array}{l}4.53,4.53, \\
4.94\end{array}\right)$ & $\left(\begin{array}{l}53.52 \\
70.64 \\
101.16\end{array}\right)$ \\
\hline
\end{tabular}

Finally, assume the FLDM control decision $\tilde{\mathrm{x}}_{1}^{1}=(1.176,1.177,1.839)$ with tolerance $\tilde{\mathrm{T}}_{1}=(1,1,1)$ and the membership function specify $\tilde{\mathrm{x}}_{1}$ and the SLDM control decision $\tilde{\mathrm{x}}_{2}^{2}=(3.667,3.667,3.667) \quad$ with tolerance $\tilde{\mathrm{T}}_{2}=(5,5,5)$ and the membership function specify $\tilde{\mathrm{x}}_{2}$. By using Equations (14) and (15), the TLDM solve the following Tchebycheff problem:

$\max \tilde{\delta}$,

subject to

$$
\begin{aligned}
& \mu_{\mathrm{x}_{\mathrm{i}}}\left(\mathrm{x}_{\mathrm{i}}\right) \geq \tilde{\delta} \mathrm{I},(\mathrm{i}=1,2), \\
& \mu_{\tilde{\mathrm{F}}_{\mathrm{i}}^{\prime}}\left(\tilde{\mathrm{F}}_{\mathrm{i}}\right) \geq \tilde{\delta} \mathrm{I},(\mathrm{i}=1,2,3), \\
& \tilde{\mathrm{x}} \in \mathrm{G}, \\
& \tilde{\mathrm{T}}_{1}, \tilde{\mathrm{T}}_{2}>0, \\
& \tilde{\delta} \in[0,1] .
\end{aligned}
$$

Let $\tilde{\delta}=\left(\delta_{1}, \delta_{2}, \delta_{3}\right)$. Use the arithmetic operations in Definition 2.2 and the bound and decomposition method ${ }^{[9]}$, then solve the constructed three Tchebycheff problems.

Therefore, the compromise fuzzy solutions are $\tilde{x}_{1}=(1.338,1.338,1.338)$,

$\tilde{x}_{2}=(1.832,1.832,2.515)$,

$\tilde{x}_{3}=(0,2.266,2.548)$,

$\tilde{F}_{1}=(12.536,31.54 .04,5859)$,

$\tilde{F}_{2}=(16.344,45.814,70.25)$,

$\tilde{F}_{3}=(18.526,59.326,84.489)$,

$\tilde{\delta}=(0.5,0.500278,0.769569)$.

\section{CONCLUSION}

This paper was focused on the solution of FFMLLP, where all of its decision parameters and variables are fuzzy numbers. An algorithm was depended on the fuzzy decision approach, bound and decomposition method were developed to find a fuzzy optimal solution for the problem under consideration. The main results obtained in this paper were clarified by an illustrative numerical example.

Finally, a numerical example was given to clarify the main results developed in this paper.

However, there are many other aspects, which should be explored and studied in the area of fuzzy multi-level optimization such as:

1. A multi-level multi-objective integer programming problem with fuzzy parameters in the objective functions.

2. A multi-level multi-objective integer programming problem with fuzzy parameters in the constraints.

3. A multi-level multi-objective integer programming problem with fuzzy parameters in both the objective functions and constraints.

\section{REFERENCES}

[1] H. J. Zimmermann, Fuzzy programming and linear programming with several objective functions, Fuzzy Sets and Systems. 1 (1978) 45-55.

[2] H. M. Nehi and H. HajMohamadi, A ranking function method for solving fuzzy multi-objective linear programming problem, Annals of Fuzzy Mathematics and Informatics. 3 (2012) 31-38.

[3] H. Tanaka and K. Asai, Fuzzy linear programming problems with fuzzy numbers, Fuzzy Sets and Systems. 13 (1984) 1-10.

[4] Y. Zhong, Y. Jia, D. Chen, and Y. Yang, Interior point method for solving fuzzy number linear programming problems using linear ranking function, Journal of Applied mathematics. (2013), Article ID 795098, 9 pages.

[5] S. H. Nasseri, E. Behmanesh, F. Taleshian, M. Abdolalipoor, N. A. Taghi-Nezhad, Fully fuzzy linear programming with inequality constraints, International Journal of Industrial Mathematics. 5 (2013) 309-316.

[6] R. Ezzati, E. Khorram, and R. Enayati, A new algorithm to solve fully fuzzy linear programming problems using the MOLP problem, Applied Mathematical Modeling. 39 (2015) 3183-3193. 
[7] B. Bhardwaj and A. Kumar, A note on 'a new algorithm to solve fully fuzzy linear programming problems using the MOLP problem', Applied Mathematical Modeling. 39 (2015) 5982-5985

[8] P. Pandian, Multi-objective programming approach for fuzzy linear programming problems, Applied Mathematical Sciences. 37 ( 2013) 1811-1817.

[9] M. Jayalakshmi and P. Pandian, A new method for finding an optimal fuzzy solution for fully fuzzy linear programming problems, I. J. of Engineering Research and Applications. 2 ( 2012) 247-254

[10] H. Zaher, N. Saeid and A. Serag, Fuzzy approach for three level linear programming problems, International Journal of Computer Applications. 133 (2016) 30-34.

[11] L. Zhang, A fuzzy algorithm for solving a class of bi level linear programming problem, Appl. Math. Inf. Sci. 8 (2014) 1823-1828.

[12] M.S. Osman, M.A. Abo-Sinna, A. H. Amer and O. E. Emam, A multi-level non-linear multi-objective under fuzziness, Applied Mathematics and Computations.153 (2004) 239-252.
[13] O. M. Saad and M. S. Hafez, An algorithm for solving bi-level integer linear fractional programming problem based on fuzzy approach", General Mathematics Notes. 3 (2011) 86-99.

[14] O. M. Saad and O. E. Emam, Taylor series approach for solving chance-constrained bi-level integer linear fractional programming problem, International Journal of Mathematical Archive. 2 (2011) 1-6.

[15] E. A. Youness, O. E. Emam and M. S. Hafez, Fuzzy bilevel multi-objective fractional integer programming, Appl. Math. and Inf. Sci. 8 (2014) 2875-2863.

[16] S. S. Hsu, Y. J. Lai, L. E. Stanley, Fuzzy approach for multi-level programming problems, Computers and Operation Research. 32 (1996) 73-91.

[17] S. S. Hsu, Y. J. Lai, L. E. Stanley, Fuzzy and multi-level decision making, Springer- Verlag Ltd, London. (2001).

[18] M. Sakawa, Fuzzy sets and interactive multi-objective optimization, Plenum Press, New York. (1993).

[19] M. A. Abo-Sinna, A bi-level non-linear multi-objective decision-making under fuzziness, Journal of Operational Research Society (OPSEARCH). 38 (2001) 484-495. 